ORIENTAL JOURNAL OF
ISSN: 0974-6471
June 2017,
COMPUTER SCIENCE \& TECHNOLOGY

\title{
Modeling and Simulation of Fiber Bragg Grating (Fbg) As A Strain Sensor
}

\author{
MUHAMMAD ARIF BIN JALIL \\ Physics Department, Faculty of Science, Universiti Teknologi \\ Malaysia, UTM, (Malaysia). \\ http://dx.doi.org/10.13005/ojcst/10.02.01 \\ (Received: June 01, 2017; Accepted: June 10, 2017)

\begin{abstract}
This study presents the modelling, simulation, and characterization of the Fiber Bragg grating (FBG) on maximum reflectivity, bandwidth, the effect of applied strain to the wavelength shift, $\check{Z}_{B}$ and sensitivity of the wavelength shift with strain for optical sensing system. In this study, a commercial FBG with the center wavelength of $1550 \mathrm{~nm}$ is used in order to measure the spectral response of FBG to strain. The parameters used in these simulations are the fiber grating length, $L$ ranging from 1 to $10 \mathrm{~mm}$, the changes in refractive index, " $\mathrm{n}$ from 0.0002 to 0.0020 , the effective refractive index, $\mathrm{n}_{\text {eff }}$ is 1.46 and the grating period of FBG, Ë for $530 \mathrm{~nm}$ in the performance of FBG. The bandwidth and spectrum reflectivity are analyzed from the variation of refractive index and grating length. Simulations on the FBG are carried out using Origin Pro 2016 and Microsoft Excel 2010 software. The Excel sheet is used to generate data and the OriginPro 2016 is used to generate the graphs. The results obtained indicates the variation in grating length and refractive index affect the spectral reflectivity and the band width. In addition, results obtained show that the changes in the Bragg wavelength are due to an increase in length of the grating region which due to the applied strain.
\end{abstract}

Keyword: Fiber Bragg Grating, Optical Sensor, Origin

Pro Software, Strain, Maximum Reflectivity, Bandwidth.

\section{INTRODUCTION}

Over the past few years, there are various components related to the industries were developed for fiber optics sensing systems. The advantages of optical fiber sensors include high sensitivity, low power consumption, wider bandwidth, and immunity to electromagnetic radiations gives wide-ranging applications in places where conventional sensors are unable to operate appropriately or not suitable with the environment involved. Throughout this study, several characteristics of FBG as an optical sensor are presented and discussed: The Bragg wavelength shift, bandwidth of full-width at halfmaximum (FWHM), reflectivity, and the changes in index of refraction. An FBG has a structure of weak coupled waveguide and the coupled-mode theory can be used in this study to analyze the 
propagation of light in optical fiber. Fiber Bragg grating has lightweight, compact size and large

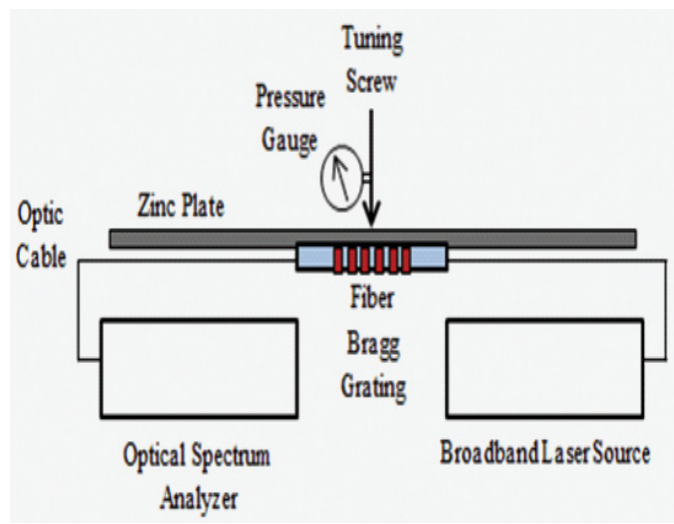

Fig. 1: The schematic model of FBG for

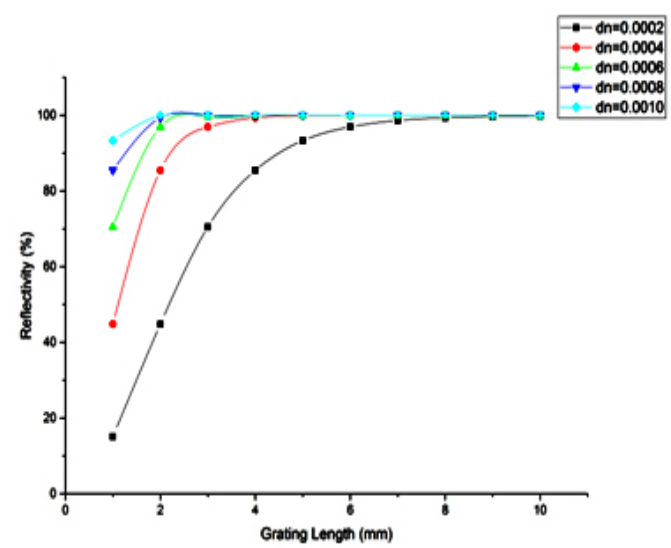

Fig. 3: The impact in the variation of grating length $(L)$ and refractive index $(\Delta n)$ ranging from 0.0002 to 0.0010 on reflectivity, $(R)$

Table 1: List of important Parameters involved in the simulation of FBG

\begin{tabular}{lcc}
\hline Parameters & Symbols & Values \\
\hline $\begin{array}{l}\text { Effective } \\
\text { refraction } \\
\text { index of } \\
\begin{array}{l}\text { Changes in } \\
\text { Grating length }\end{array}\end{array}$ & $\mathrm{n}_{\text {eff }}$ & 1.46 \\
$\begin{array}{l}\text { Bragg's } \\
\text { wavelength }\end{array}$ & $\lambda_{\mathrm{B}}$ & $1-10 \mathrm{~mm}$ \\
$\begin{array}{l}\text { Variation in } \\
\text { index of } \\
\text { refraction } \\
\begin{array}{l}\text { Period of } \\
\text { Grating }\end{array}\end{array}$ & $\Delta \mathrm{n}$ & $0.0002-0.0010$ \\
\hline
\end{tabular}

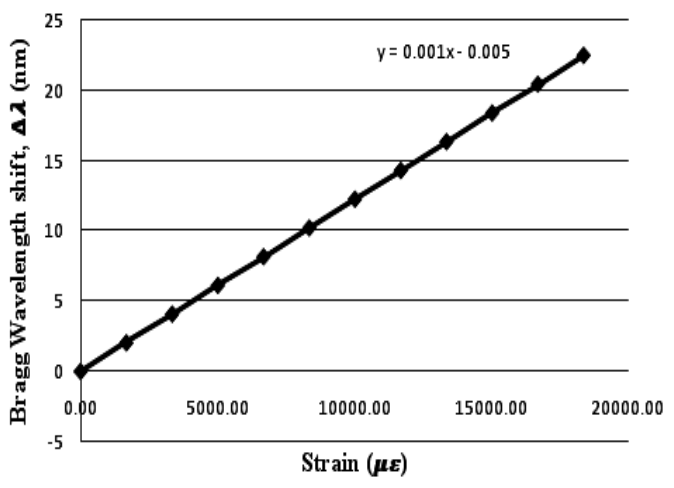

Fig. 2: The graph of Bragg wavelength shift against the applied strain

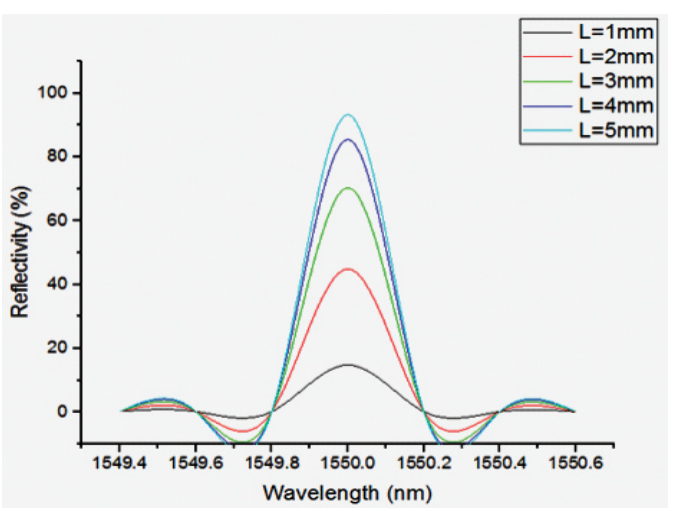

Fig. 4: The reflectivity spectrum of a uniform FBG with different value of grating length at constant change in refractive index of $\Delta \mathrm{n}=\mathbf{0 . 0 0 0 2}$

Table 2: The Bragg wavelength shift with applied strain

\begin{tabular}{lcc}
\hline $\begin{array}{l}\text { Strain } \\
(\mu \varepsilon)\end{array}$ & $\begin{array}{c}\text { Bragg } \\
\text { Wavelength, } \\
\lambda_{\mathrm{B}}( \pm 0.10 \mathrm{~nm})\end{array}$ & $\begin{array}{c}\text { Bragg } \\
\text { Wavelength shift, } \\
\Delta \lambda( \pm 0.10 \mathrm{~nm})\end{array}$ \\
\hline 0 & 1549.4 & 0 \\
1666.67 & 1549.6 & 2.04 \\
3333.33 & 1549.8 & 4.08 \\
5000 & 1550 & 6.12 \\
6666.67 & 1550.2 & 8.16 \\
8333.33 & 1550.4 & 10.21 \\
10000 & 1550.6 & 12.25 \\
11666.67 & 1550.8 & 14.29 \\
13333.33 & 1551 & 16.34 \\
15000 & 1551.2 & 18.38 \\
16666.67 & 1551.4 & 20.43 \\
18333.33 & 1551.6 & 22.47 \\
\hline
\end{tabular}


bandwidth. Thus, it is suitable to be used in strain and temperature sensing applications. The main benefits includes accurate positions in the fiber and easy to manufacture and calibrate.

\section{METHODOLOGY}

From Figure the FBG model system consists of a commercial FBG, an optical spectrum analyzer (OSA) as the detector, a broadband laser source, an optic cable to connect the FBG to OSA and laser source, a zinc plate, and a pressure gauge. The specification of the commercial FBG used in this study is given in Table 1.

In this study, a uniform FBG sensor model is being simulated with using Origin Pro software in order to obtain the spectral response. The parameters involved in the simulation of spectral responses are as listed by Table 1 .

\section{RESULTS AND DISCUSSION}

\section{Shift in Bragg's Wavelength}

From the calculated data in Table 2, a

Table 3: Variation of reflectivity (R) with the variation of grating length $(L)$ and changes in index of refraction $(\Delta \mathrm{n})$

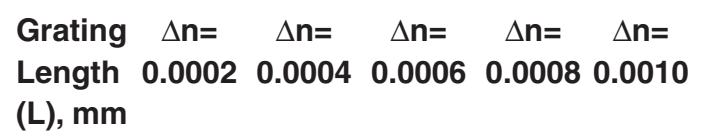

\begin{tabular}{lccccc}
\hline \multicolumn{5}{c}{ Reflectivity (R), \% } \\
\hline 1 & 15.09 & 44.84 & 70.5 & 85.49 & 93.33 \\
2 & 44.84 & 85.49 & 96.95 & 99.39 & 99.89 \\
3 & 70.5 & 96.95 & 99.73 & 99.98 & 100 \\
4 & 85.49 & 99.39 & 99.98 & 100 & 100 \\
5 & 93.33 & 99.89 & 100 & 100 & 100 \\
6 & 96.95 & 99.98 & 100 & 100 & 100 \\
7 & 98.64 & 100 & 100 & 100 & 100 \\
8 & 99.39 & 100 & 100 & 100 & 100 \\
9 & 99.73 & 100 & 100 & 100 & 100 \\
10 & 99.89 & 100 & 100 & 100 & 100 \\
\hline
\end{tabular}

graph of shift in the Bragg's wavelength against the strain applied is plotted and is shown in Figure 2 below.

\section{Spectral Reflectivity}

From Figure 3, the reflectivity increases with the rising of grating length. The FBG obtained $100 \%$ reflection when the length of grating, $L$ reach $7 \mathrm{~mm}$ while the changes in index of refraction, increase to 0.0004 . In addition, this value is maintained for longer length of grating and higher variation in index of refraction shown by Table 3 .

A graph of reflectivity versus wavelength for different grating length are shown in Figure 4. From the graph, it is clearly shown that the increase of grating length causes the increase in reflectivity which is highly desirable for reflection of FBGs.

\section{CONCLUSION}

For conclusion, the bandwidth and reflectivity spectrum were obtained with the changes in length of grating and variation in refractive index. Furthermore, the efficiency of the FBG as a strain sensor was determined. From the simulation results, the increment of grating length and refractive index increases the reflectivity. The bandwidth of FBG decreases by increasing the grating length and it increases by increasing the refractive index change. The side lobes of spectral reflectivity can be suppressed by apodization of Gaussian profile technique by using Origin Pro software.

\section{ACKNOWLEDGEMENTS}

The author would like to thank the Ministry of Higher Education of Malaysia (MOHE) and UTM for providing GUP Tier 2 (2016/2017) grants in order to conduct this research and developing the paper.

\section{REFERENCES}

1. Fahd Chaoui, O.A., Mounia Chakkour, and Mounir El Yakhloufi, Apodization Optimization of FBG Strain Sensor for Quasi-Distributed
Sensing Measurement Applications. 2016.

2. Son2, J.-W.K.a.Y.-H., Thermal Characteristics of Temperature Sensor Using Fiber 
Bragg Grating for Optical Sensor Network Communication. 2013.

3. E. Gemzický, J.M., Analysis of simulated reflection characteristics of uniform and apodized fiber bragg gratings. 2008.

4. Salo, J. and I. Korhonen, Calculated estimate of FBG sensor's suitability for beam vibration and strain measuring. Measurement, 2014. 47: p. 178-183.

5. Jin, W., et al., CHAPTER 25 - Structural Strain and Temperature Measurements Using Fiber Bragg Grating Sensors A2 - Pal, Bishnu P, in Guided Wave Optical Components and Devices. 2006, Academic Press: Burlington. p. 389-400.

6. Pereira, G., et al., On the improvement of strain measurements with FBG sensors embedded in unidirectional composites. Polymer Testing, 2013. 32(1): p. 99-105.

7. Salo, J. and I. Korhonen, Calculated estimate of FBG sensor's suitability for beamvibration and strain measuring. Measurement, 2014. 47: p. 178-183.

8. Nagwan I. Tawfik1, W.S.E., M. B. EI_ 